International Journal of Current Microbiology and Applied Sciences

ISSN: 2319-7706 Volume 10 Number 10 (2021)

Journal homepage: http://www.ijcmas.com

\title{
GC-MS Analysis of Bioactive Compounds in Lemongrass (Cymbopogon citratus) Powder
}

\author{
Pradeep P. Thorat ${ }^{1 *}$, Nikhil D. Solanke ${ }^{2}$ and Jayashri D. Ughade ${ }^{3}$ \\ ${ }^{1}$ Department of Food Business Managment, Govt. College of Food Technology, \\ Yavatmal, Akhada Balapur, Tal- Kalmnuri, Dist- Hingoli, Maharashtra, India \\ ${ }^{2}$ Department of Food Processing Technology, Govt. College of Food Technology, \\ Yavatmal, Gandhi Nagar, Tal-Pusad, Dist-Yavotmal, Maharashtra, India \\ ${ }^{3}$ Department of Agricultural Entomology, Govt. College of Food Technology, \\ Yavatmal, Maharashtra, India \\ *Corresponding author
}

\section{A B S T R A C T}

Keywords

Bioactive

compound,

Chromatography,

GC/MS,

Lemongrass,

Phytocompound

Article Info

Accepted:

10 September 2021

Available Online:

10 October 2021
The bioactive components of lemongrass powder have been evaluated using GC-MS. The GC-MS analysis was performed on GC-MS comprising an automatic liquid sampler and agilent gas chromatograph interfaced to mass spectrometer (GC-MS). Interpretation of the mass spectrum GC-MS was conducted using the database of National Institute Standard and Technology (NIST). The compound bioactivity prediction is based on Dr. Duke's phytochemical and ethnobotanical Database. GC/MS analysis of methanolic extract of lemongrass leaves revealed the existence of Pentane, 2,4-Dimethyl, Dodecanoic acid tert-butyl ester, 2,6 Bis (1,1-dimethylethyl)4-[(4-chloro-6-(3,5, bis (1,1-dimethylethyl)-4- hydroxyanilino)-1,3,5triazin-2-yl)amino]phenol and 3-Formyl-4,5-dimethyl-pyrrole. The presence of these compounds in the plant extract may at least be responsible for the pharmacological properties of Cymbopogon citratus and thus recommended as plant of phytopharmaceutical importance.

\section{Introduction}

Medicinal plants are source of a great economic value. Plant herbs are naturally gifted at the synthesis of medicinal compounds. Medicinal plants are used in herbalism and known for their medicinal properties. Medical Plant constitutes an important therapeutic aid in alleviating ailments. The traditional medicine or medicinal plants are used at normative basis for maintenance of good health in developing countries (UNESCO, 1996). The extraction and characterization of bioactive compounds 
from medicinal plants have resulted in the discovery of new drugs with high therapeutic value. Treatment using medicines of natural origin is gaining momentum nowadays on account of increasing concern about potentially harmful synthetic additives (Reische, 1998). Cymbopogan citratus is a great interest due to its commercially valuable essential oils and widely used in food technology as well as in traditional medicine. Due to increased demand of natural products from medicinal plants in healthcare serves worldwide, herbal plant producers have commenced the use of different extraction methods in order to see and detach the chemical compounds present in them (Achi and Ohaeri, 2015). The main intent of detection of phytocompound in plants is to arrive at the therapeutically desired active portion/fraction and to purge superfluous materials (Waldesch et al., 2003). An exceptional facet of advanced plants is their competence to manufacture various organic chemicals of high structural density (Achi and Ohaeri, 2015). The awareness of the chemical constituents of plants is not only advantageous for discovery of curative agents but also for disclosing new sources of important economic phytocompounds for the synthesis of complex chemical substances and for discovering the actual significance of folklorica (Uraku et al., 2015).

The aim of this study is to determine the organic compounds present in the cymbopogon citratus powder with the aid of GC-MS technique, which may provide an insight in its use in traditional medicine.

\section{Materials and Methods}

\section{Collection and identification of plant material}

Fresh leaves of Cymbopogon citratus were collected and authenticated from Department of Botany, Vasantrao Naik Marathwada Krishi Vidyapeeth, Parbhani (India).

\section{Preparation of plant material}

The leaves of Cymbopogon citratus were sorted, washed thoroughly with distilled water to remove dirt and debris, cut into smaller pieces before these was cabinet dried for $5 \mathrm{hrs}$ at $45^{\circ} \mathrm{C}$ temperature. The dried leaves were pulverized into fine powder. The powdered materials were stored in air tight polyethene bags protected from direct sunlight until required for use.

\section{Preparation of lemongrass leaves extract}

The extraction of leaves was carried out with slight modification in method given by Uraku, (2015). Forty grams of the powdered leaves were extracted with $100 \mathrm{~mL}$ of $40 \%$ methanol overnight in a stopped bottle and with occasional stirring at room temperature $\left(28 \pm 3^{0} \mathrm{C}\right)$. The sample was first sieved using muslin cloth and then filtered using Whatman No. 1 filter paper. This process was repeated three times. The filtrate was concentrated under reduced pressure at $40^{\circ} \mathrm{C}$ for $45 \mathrm{~min}$ in a rotary vacuum evaporator and then lyophilized to get a brown aromatic solid extract. The dry extract obtained was kept in a refrigerator at $4^{\circ} \mathrm{C}$ until required for use.

\section{GC-MS analysis}

The GC-MS analysis was done with modification in the method given by Uraku (2015) and Thenmozhi and Rajan (2015). The analysis was performed at Sophisticated Analytical Instrument Facility (SAIF), Indian Institute of Technology (IIT), Bombay.

The GC-MS analysis was performed on GCMS (Model: The AccuTof JMS-T100GCV, JEOL ltd., Tokya, Japan) comprising an automatic liquid sampler and agilent gas 
chromatograph interfaced to mass spectrometer (GC-MS). The instrument has EI ion source, low acceleration ion-transfer system, reflection type TOF analyser, dual micro channel plate ion detector and the ventilation facility for rotary pump.

The instrument is equipped with capillary column (Rxi-5 ms, manufactured by Restek Corporation, Bellefonte, Pennsylvania, US) of $60 \mathrm{~m}$ length, $0.25 \mathrm{~mm}$ diameter and $0.25 \mu \mathrm{m}$ thickness. For GC-MS detection, an electron ionization system was used with ionization energy of $70 \mathrm{eV}$. Helium was the carrier gas, at a flow rate of $1 \mathrm{ml} / \mathrm{min}$ and an injection volume of $0.5 \mu \mathrm{I}$ was employed (split ratio of 10:1). The injector and MS transfer line temperature were set at 220 and $290^{\circ} \mathrm{C}$ respectively.

The oven temperature was programmed from $80^{\circ} \mathrm{C}$ (isothermal for $3 \mathrm{~min}$ ) with an increase of at $8^{\circ} \mathrm{C} / \mathrm{min}$ to $200^{\circ} \mathrm{C}$, increasing at $8^{\circ} \mathrm{C} / \mathrm{min}$ (isothermal for $3 \mathrm{~min}$ ) reached to $275^{\circ} \mathrm{C}$, then $5^{\circ} \mathrm{C} / \mathrm{min}$ to $280^{\circ} \mathrm{C}$, ending with $5 \mathrm{~min}$ isothermal at $280^{\circ} \mathrm{C}$. Mass spectra were taken at $70 \mathrm{eV}$, a scan interval of $0.5 \mathrm{sec}$ and fragments from 50 to $500 \mathrm{~m} / \mathrm{z}$. The total running time of GC-MS was $31 \mathrm{~min}$.

\section{Identification of components}

Interpretation of the mass spectrum GC-MS was conducted using the database of National Institute Standard and Technology (NIST) having more than 62,000 patterns. The fragmentation pattern spectra of the unknown components were compared with those of known components stored in the NIST library (NIST, 2010).

The compound bioactivity prediction is based on Dr. Duke's phytochemical and ethnobotanical Database (Duke, 2014). The relative percentage amount of each phytocomponent was calculated by comparing its average peak area to the total area. The name, molecular weight and structure of the components of the test materials were ascertained.

\section{Results and Discussion}

Four compounds were identified in lemongrass powder by GC-MS analysis. The retention time (RT), retention value, molecular formula and molecular weight were presented in Table 1.

In the present research study, the GC-MS analysis of methanol extract of lemongrass (Cymbopogon citratus) revealed that the lemongrass contained a wide range nutraceutical compounds which may be responsible for its therapeutic potential.

The identified phytocompounds comprise mainly hydrocarbons, fatty acids, alcohol, esters and phenols. Among the compounds present in the lemongrass extract include, Pentane 2,4-Dimethyl, Dodecanoic acid tertbutyl ester, 2,6 Bis (1,1-dimethylethyl)-4-[(4chloro-6-(3,5, bis (1,1-dimethylethyl)-4hydroxyanilino)-1,3,5-triazin-2-yl)amino] phenol and 3-Formyl-4,5-dimethyl-pyrrole.

The GC-MS method confirms that lemongrass powder contain Pentane, 2,4-Dimethyl, Dodecanoic acid tert-butyl ester, 2,6 Bis $(1,1-$ dimethylethyl)-4-[(4-chloro-6-(3,5, bis (1,1-di methylethyl)-4- hydroxyanilino)-1,3,5-triazin2-yl) amino]phenol and 3-Formyl-4,5dimethyl-pyrrole.

The biological activities listed (Table 2) are based on Dr. Duke's Phytochemical and Ethnobotanical Databases by Dr. Jim Duke of the Agricultural Research Service (2013). The pentane, 2,4-Dimethyl were obtained at 6.22 min retention time by GC-MS analysis of lemongrass has retention value $589 \mathrm{iu}$. 
Table.1 GC-MS analysis of lemongrass (Cymbopogon citratus) extract

\begin{tabular}{|c|c|c|c|c|c|}
\hline Peak\# & Compound Name & $\begin{array}{c}\text { Retention } \\
\text { time (min) }\end{array}$ & $\begin{array}{c}\text { Retention } \\
\text { value (iu) }\end{array}$ & $\begin{array}{c}\text { Molecular } \\
\text { formula }\end{array}$ & $\begin{array}{c}\text { Molecular weight } \\
\text { (g/mol) }\end{array}$ \\
\hline $\mathbf{1}$ & Pentane, 2,4-Dimethyl & 6.22 & 589 & $\mathrm{C}_{7} \mathrm{H}_{16}$ & 100.205 \\
\hline $\mathbf{2}$ & Dodecanoic acid tert-butyl ester & 8.28 & 1694 & $\mathrm{C}_{16} \mathrm{H}_{32} \mathrm{O}_{2}$ & 256.43 \\
\hline $\mathbf{3}$ & $\begin{array}{c}2,6 \text { Bis (1,1-dimethylethyl)-4-[(4-chloro-6-(3,5, } \\
\text { bis (1,1-dimethylethyl)-4- hydroxyanilino)-1,3,5- } \\
\text { triazin-2-yl)amino]phenol }\end{array}$ & 15.05 & 4361 & $\mathrm{C}_{31} \mathrm{H}_{44} \mathrm{CIN}_{5} \mathrm{O}_{2}$ & \\
\hline $\mathbf{4}$ & 3-Formyl-4,5-dimethyl-pyrrole & 29.24 & 1167 & & \\
\hline
\end{tabular}

Table.2 Biological activity of lemongrass components identified by GC-MS

\begin{tabular}{|c|c|c|}
\hline Name of the Compound & Type of Compound & Biological Activity \\
\hline $\begin{array}{c}\text { Pentane 2,4-Dimethyl } \\
\text { Dodecanoic acid tert-butyl ester }\end{array}$ & Alkane & $\begin{array}{c}\text { Antiashtmatics, antipruritics, } \\
\text { antipsoriatics, flavour }\end{array}$ \\
\hline $\begin{array}{c}\text { 2,6 Bis (1,1-dimethylethyl)-4-[(4-chloro-6-(3,5, bis (1,1- } \\
\text { dimethylethyl)-4-hydroxyanilino)-1,3,5-triazin-2- } \\
\text { yl)amino]phenol }\end{array}$ & Phenol & NF \\
\hline 3-Formyl-4,5-dimethyl-pyrrole & Carboxyaldehyde & NF \\
\hline
\end{tabular}


Fig.1 Chromatogram (Major peaks) obtained from GC-MS analysis of lemongrass (Cymbopogon citratus) extract

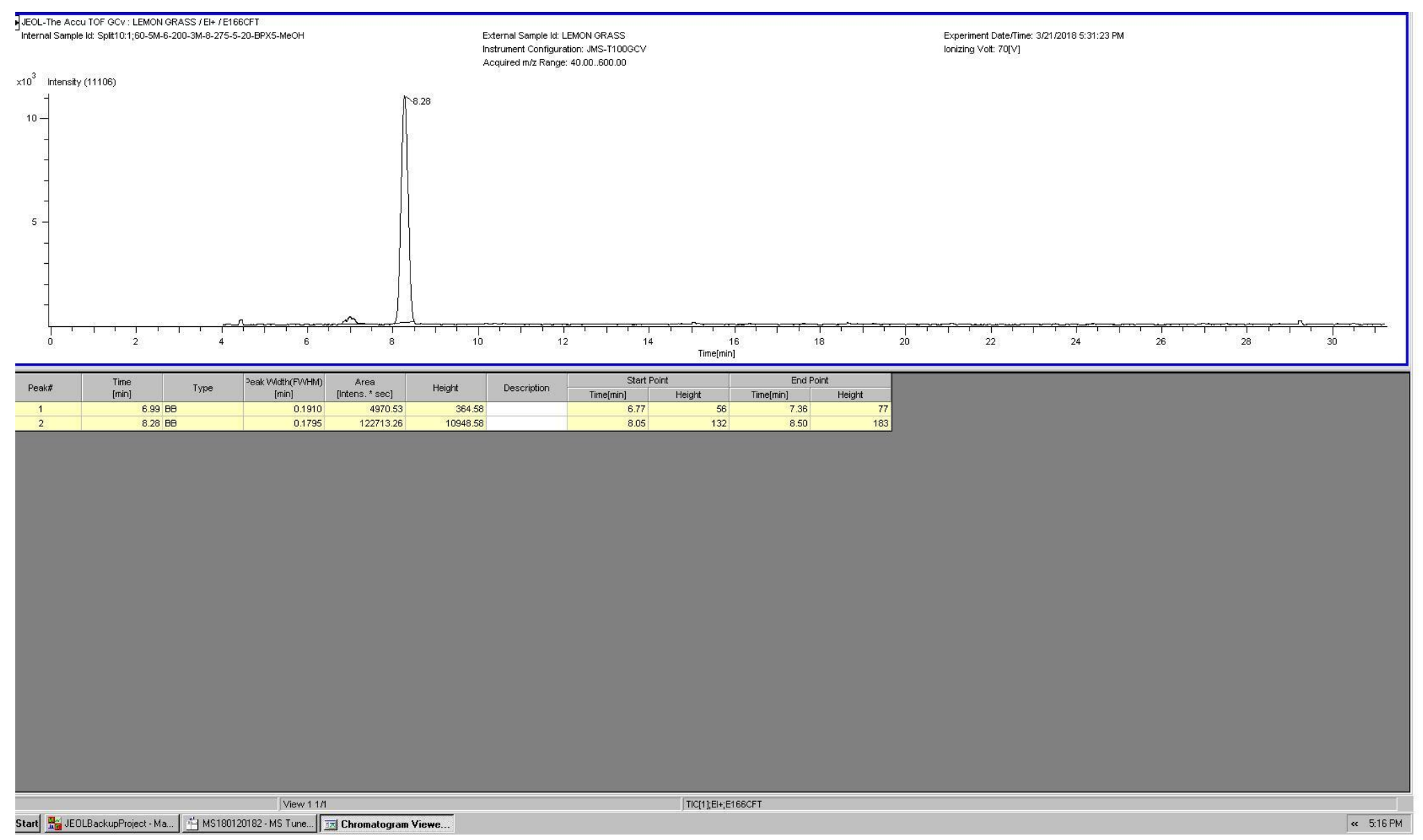


Fig.2 Molecular structure of nutraceutical compounds obtained by GC-MS from lemongrass (Cymbopogon citrates) extract

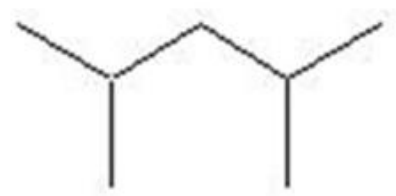

Pentane, 2,4-Dimethyl

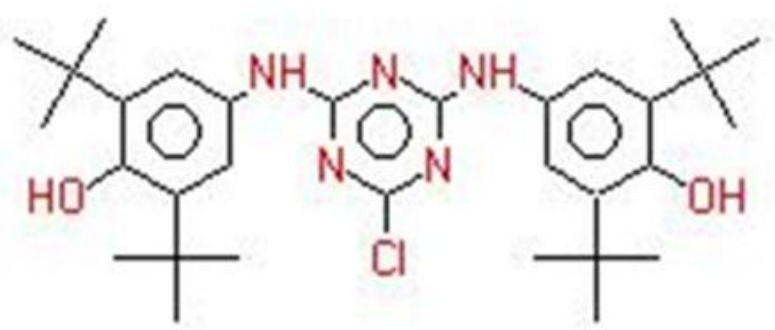

2,6 Bis (1,1-dimethylethyl)-4-[(4-chloro-6-(3,5, bis (1,1dimethylethyl)-4- hydroxyanilino)-1,3,5-triazin-2-yl)amino]phenol

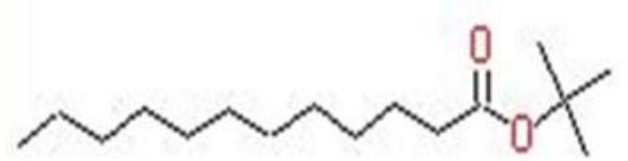

Dodecanoic acid tert-butyl ester

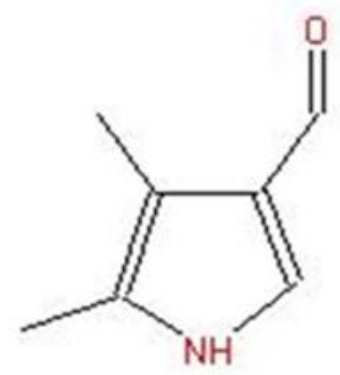

3-Formyl-4,5-dimethyl-pyrrole 
The molecular formula is $\mathrm{C}_{7} \mathrm{H}_{16}$ and molecular weight is $100.205 \mathrm{~g} / \mathrm{mol}$. It is also known as 2,4-Dimethypentane. It was found that pentane 2,4-penatne has anti-cancerous activity.

The dodecanoic acid tert-butyl ester were obtained by GC-MS analysis of lemongrass extract. The retention time and value for this compound were $8.28 \mathrm{~min}$ and $1694 \mathrm{iu}$. The molecular formula is $\mathrm{C}_{16} \mathrm{H}_{32} \mathrm{O}_{2}$ with molecular weight $256.43 \mathrm{~g} / \mathrm{mol}$. It is also known as dodecanoic acid 1,1-dimethylethylester, lauric acid tert-butyl ester, tert-butyl dodecanoate and tert-butyl laurate. It has antiashtmatics, antipruritics, antipsoriatics and flavour activities.

The phenolic compound 2,6 Bis $(1,1-$ dimethylethyl)-4-[(4-chloro-6-(3,5, bis $(1,1$ dimethylethyl)-4-hydroxyanilino)-1,3,5-

triazin-2-yl)amino]phenol was obtained at retention time $15.05 \mathrm{~min}$ has retention value 4361 iu. The molecular formula is $\mathrm{C}_{31} \mathrm{H}_{44} \mathrm{CIN}_{5} \mathrm{O}_{2}$ with having molecular weight $553 \mathrm{~g} / \mathrm{mol}$. There is no synonym were found and also there is no any evidence for its biological activities.

The 3-formyl-4,5-dimethyl-pyrrole was obtained at retention time $29.24 \mathrm{~min}$ with retention value 1167 iu from GC-MS analysis of lemongrass extract. The molecular formula is $\mathrm{C}_{7} \mathrm{H}_{9} \mathrm{NO}$ with molecular weight $123 \mathrm{~g} / \mathrm{mol}$.

The GC-MS analysis of lemongrass (Cymbopogon citratus) confirms the presence of enlisted nutraceutical compounds which aid medicinal, nutraceutical and therapeutic value. The presence of these compounds were not identified in the past research studies except nhexadecanoic acid in lemongrass extract (Uraku, 2015). Most of the studies were conducted on the lemongrass essential oil to isolate and characterize the bioactive compounds.
The GC-MS analysis revealed that the leaf extract of Cymbopogon citratus contained Pentane, 2,4-Dimethyl, Dodecanoic acid tertbutyl ester, 2,6 Bis (1,1-dimethylethyl)-4-[(4chloro-6-(3,5, bis (1,1-dimethylethyl)-4hydroxyanilino)-1,3,5-triazin-2-yl) amino] phenol and 3-Formyl-4,5-dimethyl-pyrrole. The presence of these phytocompounds may be responsible for its popular use in treatment of numerous diseases by traditional users.

\section{References}

Achi, N. K. and Ohaeri, O. C. (2015). GC-MS determination of bioactive constituents of the methanolic fractions of Cnidoscolus aconitifolius. $\mathrm{Br} . \quad \mathrm{J}$. Pharm. Res., 5: 163-172.

Duke J A (2013). Phytochemical and Ethnobotanical Databases. Phytochemical and Ethnobotanical Databases. www.ars-gov/cgibin/duke/.2013.

Duke J A (2014). Dr. Duke's Phytochemical and ethnobotanical databases. http://www.arsgrin.gov/cgibin/duke/ethnobot.pl

NIST, (2010). Automated mass spectral library with search program (Data version: NIST11, version 2.0). National Institute of Standards and Technology, Gaithersburg, MD., USA.

Reische, D. L. (1998). Antioxidant in food lipids. In i. C. (Eds.), Chemistry, Nutrition and Biotechnology, New York: Marcel Dekker, pp: 423-448.

Thenmozhi, S. and Rajan, S. (2015). GC-MS analysis of bioactive compounds in Psidium guajava leaves. $J$. Pharmacognosy and Phytochem., 3(5): 162-166.

UNESCO, (1996). Culture and Health, Orientation Texts - World Decade for Cultural Development 1988 - 1997, Document CLT/DEC/PRO - Paris, France, 129. 
Uraku, A. J. (2015). Determination of chemical compositions of Cymbopogon citratus leaves by Gas Chromatography-Mass Spectrometry (GC-MS) method. Res. J. Phytochem., 9(4): 175-187.

Uraku, A. J., Offor, C. E., Itumoh, E. J., Ukpabi, C. E. and Aja, P. M. (2015). Gas Chromatography-Mass
Spectrometry (GC-MS) analysis of essential oil from Hyptis spicigera leaves. Am. J. Biol. Chem., 3: 45-56.

Waldesch, F. G., Konigswinter, B. S. and Blasius, H. (2003). Herbal Medicinal Products, Medpharm, Stuttgart, Germany. CRS Press, London, pp: 4854.

How to cite this article:

Pradeep P. Thorat, Nikhil D. Solanke and Jayashri D. Ughade. 2021. GC-MS Analysis of Bioactive Compounds in Lemongrass (Cymbopogon citratus) Powder. Int.J.Curr.Microbiol.App.Sci. 10(10): 283-290. doi: https://doi.org/10.20546/ijcmas.2021.1010.034 